\title{
SELECCIÓN DE RECETAS DEL CURSO"CULTURA MATERIAL E INMATERIAL" DEL PROGRAMA PROFESIONAL EN GASTRONOMÍA Y ALTA COCINA UNAB
}

Dirigido por el profesor Manuel Ernesto Acebedo Martínez 


\section{SELECCIÓN DE RECETAS DEL CURSO"CULTURA MATERIAL E INMATERIAL" DEL PROGRAMA PROFESIONAL EN GASTRONOMÍA Y ALTA COCINA UNAB}

En el marco de la cátedra "cultura material e inmaterial" del programa Profesional en Gastronomía y Alta Cocina de la UNAB, se ha puesto en marcha un proceso de salvaguardia del patrimonio cultural inmaterial (PCI) gastronómico de Santander en el cual se involucra a la comunidad estudiantil y se propende por la integración de herramientas de aprendizaje e investigación.

Derivado de la normatividad de la UNESCO sobre salvaguarda del PCI (que ha sido adoptada por Colombia a través del Ministerio de Cultura y el Instituto Colombiano de Antropología e Historia) y acorde a los lineamientos del PEI-UNAB sobre "dimensiones del ser humano", se ha desarrollado una propuesta de investigación en el marco de una de las cátedras de segundo semestre. La intensión de la misma es propender por un proceso integral de salvaguardia en el cual se ofrezca a los estudiantes las herramientas epistemológicas y metodológicas necesarias para la identificación y promoción de hitos patrimoniales de la gastronomía.

Como resultado de dicho proceso de investigación en fuentes secundarias (libros especializados en historia, historia de la alimentación y gastronomía, tanto de Colombia como de otros países cuya influencia en la gastronomía nacional es evidente) y fuentes primarias (testimonios de individuos portadores de "conocimiento ancestral" sobre gastronomía) se han concretado un grupo de productos audiovisuales en los cuales los estudiantes exponen un "plato típico" de alguna región de Colombia, adentrándose en los pormenores históricos y geográficos que son su impronta y dándole un toque de innovación a partir de gustos y pareceres individuales.

De esta manera, al día de hoy se cuenta con un vasto grupo de producciones audiovisuales que contienen información histórica, geográfica, nutricional y cultural sobre algunas de las creaciones culinarias más destacadas de Santander y algunas otras partes del país.

Manuel Ernesto Acebedo Martínez

Docente del Programa de Gastronomía y Alta Cocina

Universidad Autónoma de Bucaramanga

Correo electrónico: macebedo353@unab.edu.co 


\section{SUSHI SANTANDEREANO}

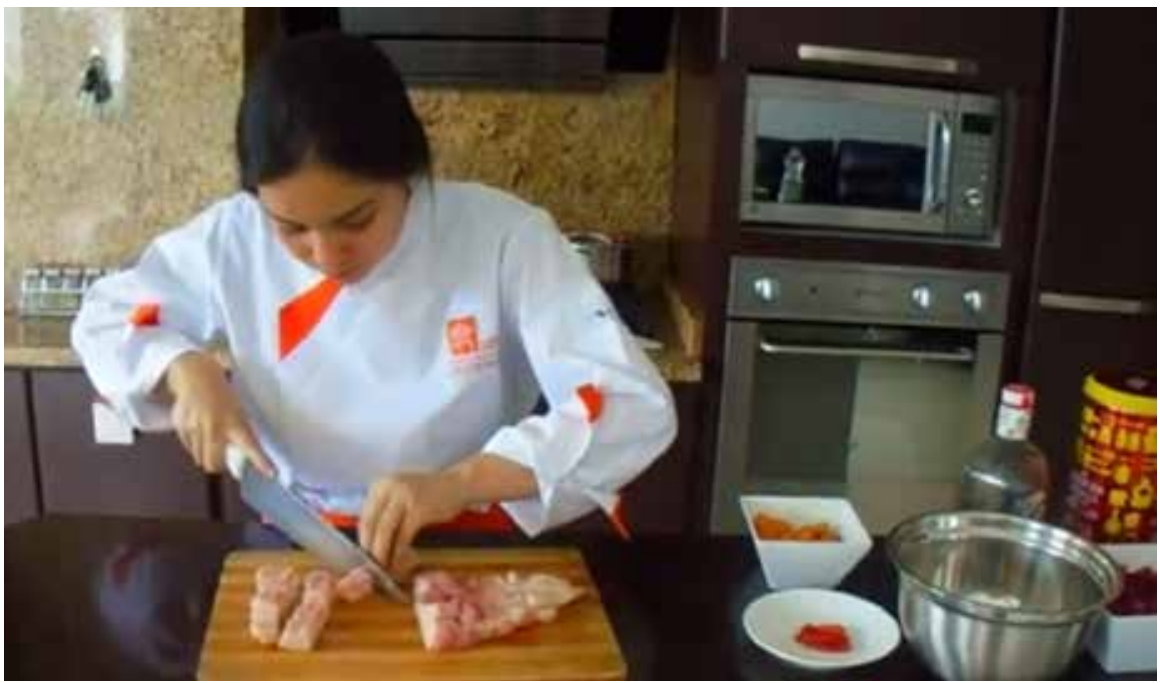

https://www.youtube.com/watch?v=xnj8Nnd08Tk\&t=11s

\section{LASAGNA COLOMBIANA}

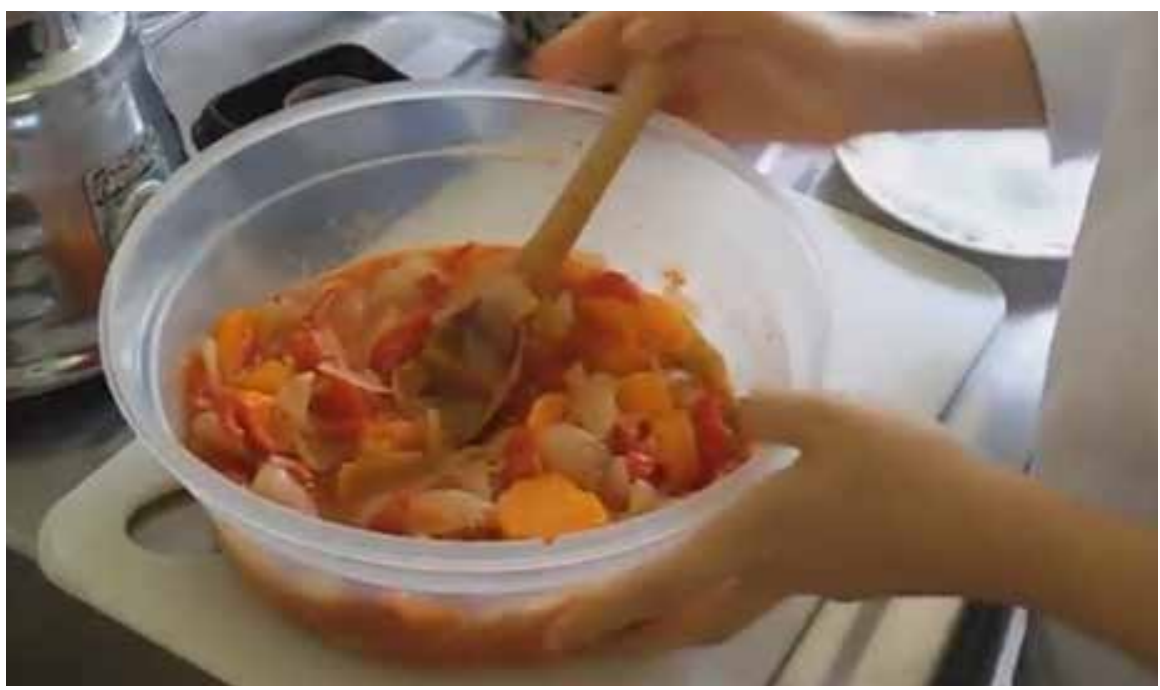

https://www.youtube.com/watch?v=Sr517uFUzrs\&t=24s
Video de la receta y preparación del plato "Sushi santandereano", realizada por las estudiantes Mónica Anaya y Gabriela Blanco.

Video de la receta y preparación del plato "Lasgna colombiana", realizada por los estudiantes María D. Sierra y Julián Martínez. 
Video de la receta y preparación del plato "Arepa e' huevo fusión", realizada por los estudiantes José Miranda y Gabriel Abril.

Video de la receta y preparación del plato "Cazón y arepa de maiz.", realizada por los estudiantes Jaime Henriquez y Joham Quintana.
AREPA E' HUEVO FUSION

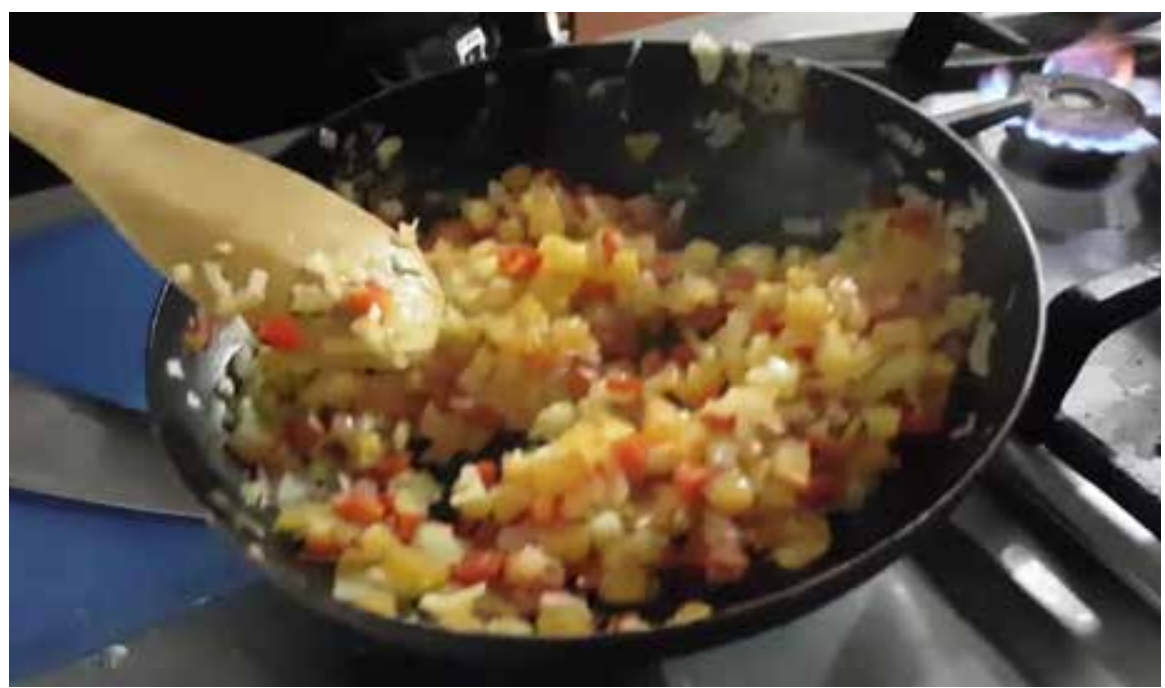

https://www.youtube.com/watch?v=SsQrRIZwAsU

CAZÓN Y AREPA DE MAIZ

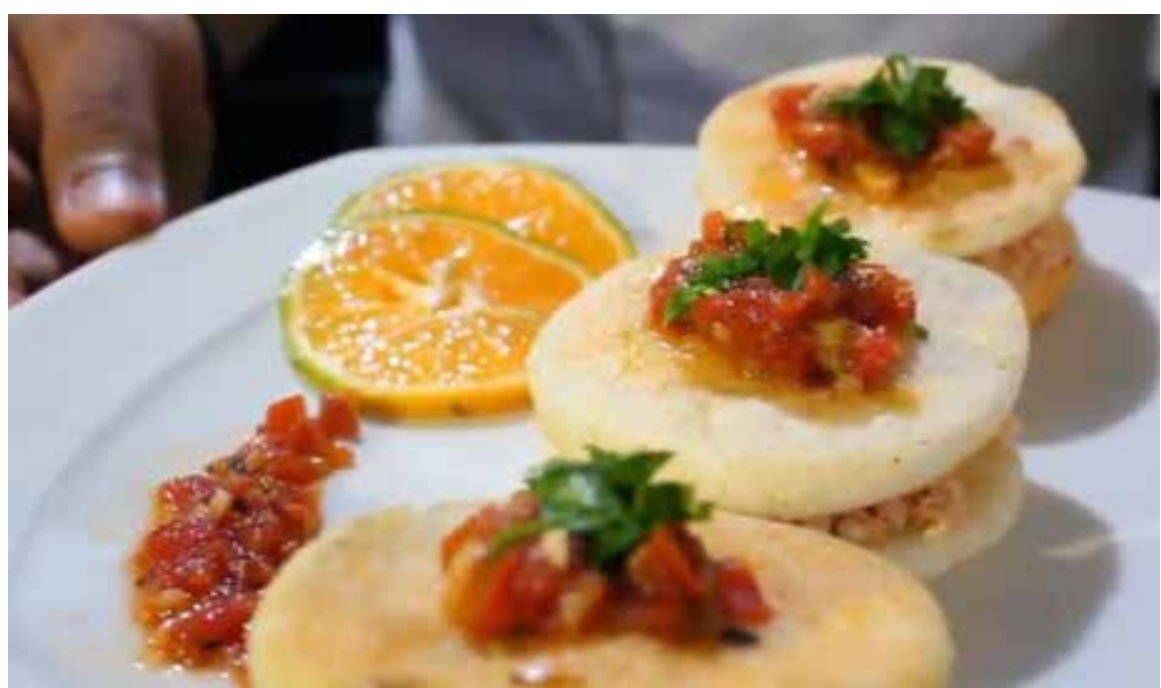

https://www.youtube.com/watch?v=rgwosegDkho 